\author{
EDUARDO BÁEZ M.
}

INSTITUTO DE INVESTIGACIONES ESTÉTICAS, UNAM

\title{
Réquiem por un claustro
}

N CLAUSTRo QUE envejece, que enfermó hace tiempo, que se muere piedra a piedra; que se muere en cada pilastra, en cada cornisa y en cada capitel, asomado a un tiempo de casi cuatrocientos años. Como una dolorosa metáfora del tiempo.

Un claustro que tuvo vida y que hoy se hunde día con día en la mayor soledad, hacia la soledad absoluta que es la muerte, como dijera M iguel de Unamuno. Q ue se pierde ante la indiferencia con que miramos nuestra historia y nuestro patrimonio cultural. Tal es el caso, en este irse muriendo, del claustro del convento carmelita de Atlixco, antigua Villa de C arrión.

Un claustro que vemos que se va perdiendo y que dejaremos perder. ¿Q ué hay de misterioso en todos esos edificios que vemos perecer, sin atrevernos a salvar? ¿Q ué sino fatal o maldito, o qué tabú nos ha impedido protegerlos y rescatarlos? Porque tal parece que hay una mezcla de miedo, indecisión y morbo, y una actitud decadentista en nuestra impotencia para agitar los brazos y gritar y blasfemar si fuera necesario, con tal de salvar estos testigos pétreos de nuestra herencia colonial.

Este claustro es lo que queda del convento carmelita del siglo xvir, junto con la desvencijada nave de la iglesia, la portería y alguna otra cosa de menor significación.

Los carmelitas descalzos llegaron a la Nueva España en 1585, aún en vida de San Juan de la Cruz y cuando se debatía en los capítulos generales si debían pasar a evangelizar en tierra americana 0 si debían guardar su estatuto de orden estrictamente contemplativa, encerrados en sus celdas y entregados a la meditación. Finalmente pasaron, pero no hicieron evangelización, sino 

156
EDUARDO BÁEZ M.

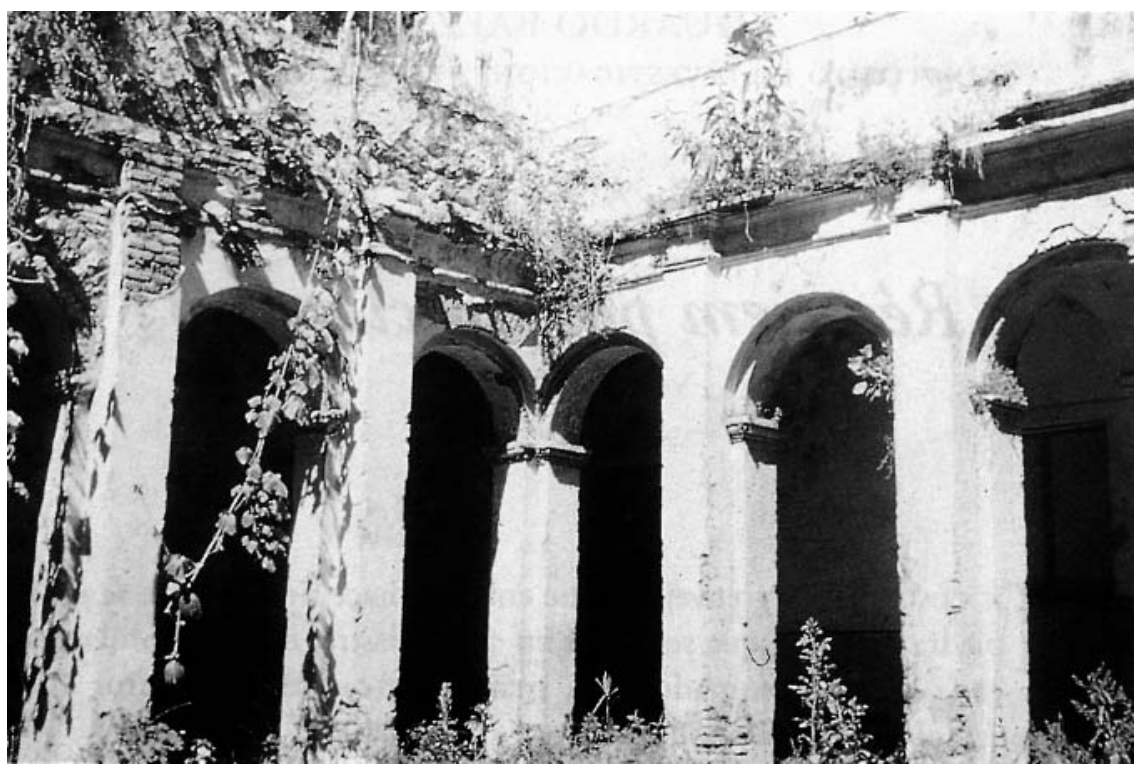

Foto ı. El claustro hace 30 años. Foto: Eduardo Báez.

que se quedaron en la ciudad de M éxico, en donde fundaron su primer convento, en el barrio de San Sebastián. Al año siguiente se instalaron en Puebla, en la ermita dedicada a la Virgen de los Remedios, que transformaron en su segundo convento. $Y$ solamente tres años después decidieron fundar un tercer monasterio en la antigua Atlixco, que desde is79 ostentaba ya el título de Villa de Carrión. Les atraía la fertilidad del valle irrigado por el Atoyac, según lo describen las crónicas: "es valle de las mejores tierras y más fértiles de la N ueva España, porque riega sus tierras el río Atoyac, como a Egipto el Nilo...". .

Rodean a la villa medianos cerros, pero uno en especial es importante: el cerro de San M iguel, que la guarda como el guerrero vigilante guarda sus tesoros. Por esto ostenta en su escudo de armas, en la partición derecha, a San M iguel Arcángel, que en actitud bélica surca el espacio blandiendo la espada.

Los carmelitas fundaron el convento el 28 de septiembre de 1589 y colo-

I. M arco D íaz, Antigua Villa de Carrión, M éxico, Centro Regional de Puebla, 1987. 
DOI: http://dx.doi.org/10.22201/iie.18703062e.1995.66.1728

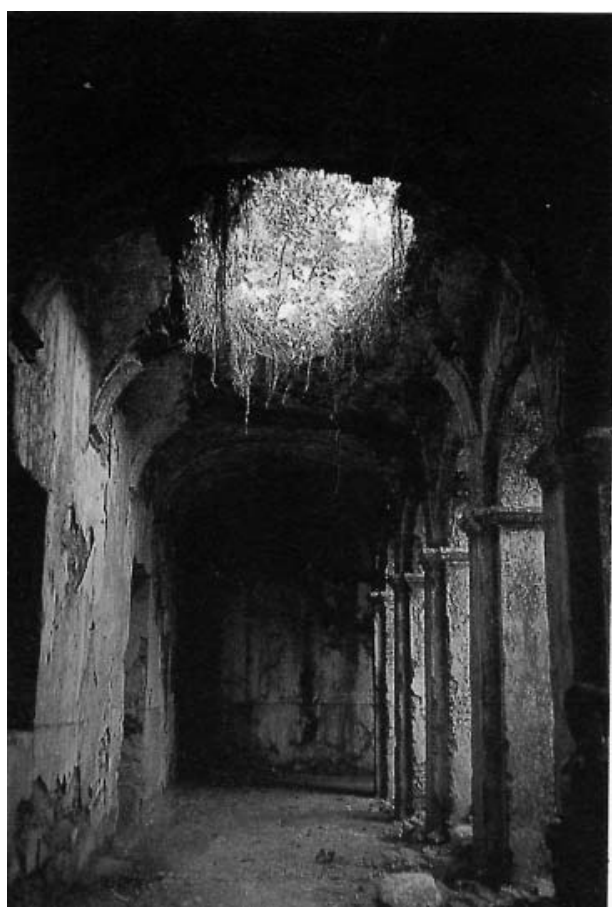

Foto 2. El claustro hace io años. Foto: E.B.

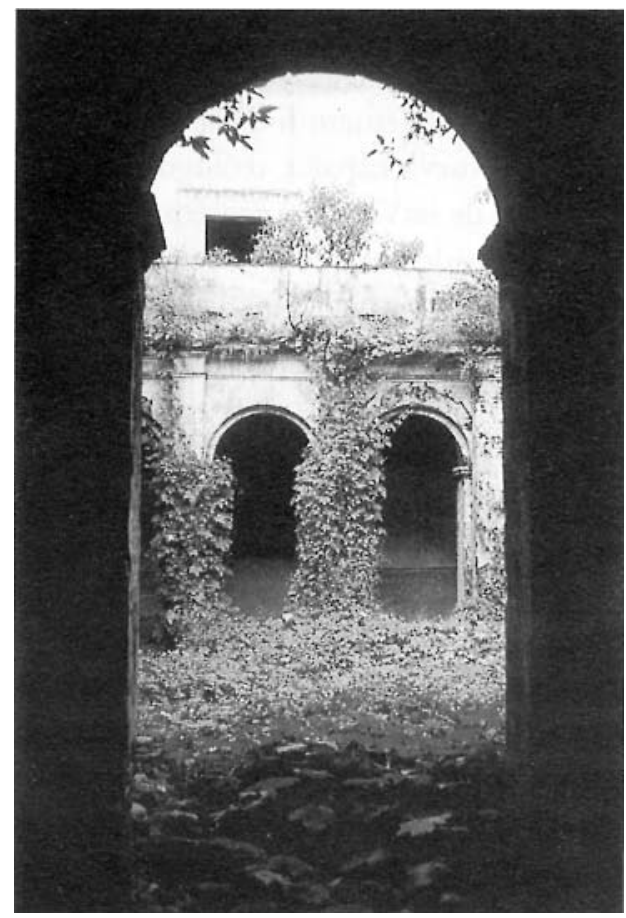

Foto 3. El claustro hace so años. Foto: E.B. 
caron el Santísimo el 22 de octubre siguiente, en unas casas donadas por el vecino $\mathrm{H}$ ernán Pérez de $\mathrm{O}$ larte. La crónica de la provincia, escrita por fray Agustín de la M adre de Dios, ${ }^{2}$ consigna los nombres de los primeros fundadores: fray Juan de Jesús M aría, fray Pedro de la M agdalena, fray Francisco Bautista de la M agdalena, fray Elías de San Juan Bautista, fray M artín de los Ángeles, fray Ángel de la $\mathrm{N}$ atividad y fray Francisco de la Concepción.

Fue una casa pobre e incómoda, como toda capilla improvisada, hasta que se emprendió la obra definitiva bajo el priorato de N icolás de San Alberto (I604-I6I2), concluyéndose entre los años I6I6 y I6I8, en el segundo priorato del mismo fray N icolás. H acia i62o estaba el monasterio casi concluido, como se desprende de la autorización concedida en dicho año para que en la capilla mayor se diera sepultura a la madre del provincial fray Rodrigo de San Bernardo. Es curioso que en este caso los indicios de conclusión del claustro resulten más tardíos, hasta los años i624 y i627, que el resto del monasterio.

El arquitecto que concibió este edificio era un hermano lego de la misma orden descalza, andaluz de nacimiento y Andrés Segura de nombre, que al hacerse religioso mudó por el de fray Andrés de San M iguel. Personaje de los más grandes del siglo xvir, fue constructor de monasterios, acueductos y puentes, ingeniero hidráulico, autor del único tratado de arquitectura escrito en la N ueva España, teólogo preocupado por demostrar matemáticamente la gracia de la $V$ irgen y matemático delirante que intentó calcular el número de semillas de col que podrían caber en una esfera del tamaño de la tierra. Fue sabio en muchas cosas más y entretenido narrador por añadidura, como se puede apreciar en la relación del naufragio que padeció durante su viaje a las Indias, ${ }^{3}$ y en el cual se anticipa en tiempo y aventaja en ingenio y donosura a los Infortunios de Alonso Ramírez publicados por Carlos de Sigüenza y Góngora.

Trabajó fray Andrés, directa o indirectamente, en todos los conventos de primera generación de los carmelitas descalzos de la Provincia de San Alberto: San Sebastián de M éxico, Puebla, Atlixco, C elaya, Q uerétaro, Valladolid, San Ángel, Cuajimalpa y Salvatierra, además de los servicios que prestó al

2. Agustín de la M adre de Dios, Tesoro escondido en el M onte Carmelo M exicano, M éxico, Universidad Nacional Autónoma de M éxico, Instituto de Investigaciones Estéticas, I986, p. 48.

3. $O$ bras de fray Andrés de San M iguel, M éxico, U niversidad N acional Autónoma de M éxiCo, Instituto de Investigaciones Estéticas, 1969. 


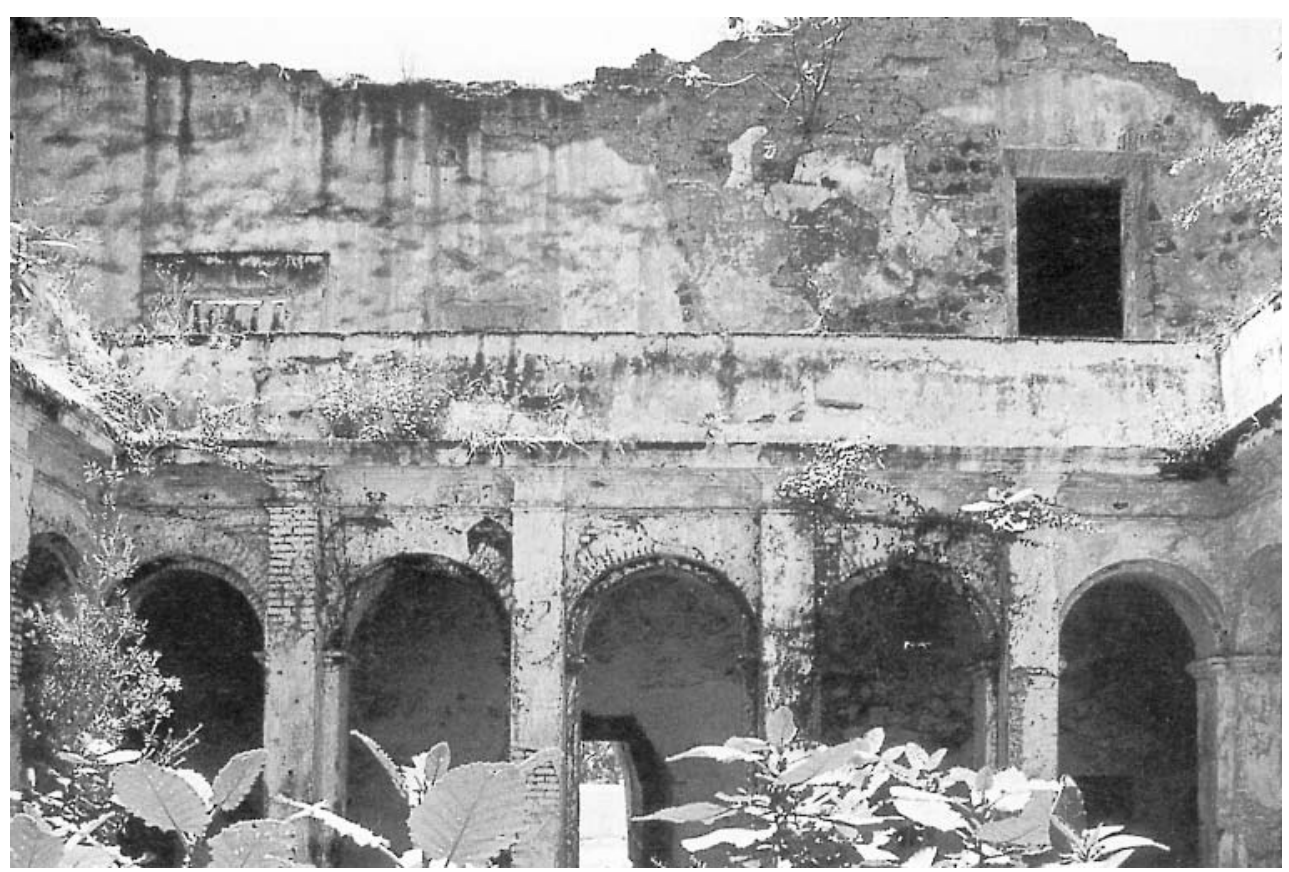

Foto 4. El claustro en 1994. Foto: Archivo Fotográfico M anuel Toussaint, Instituto de Investigaciones Estéticas (en adelante IIE).

gobierno virreinal para el desagüe de la ciudad de M éxico. En el caso de Atlixco, las partes que podemos considerar originales y que aún están de pie son la portería, la iglesia y el claustro, los tres en ruinas.

La nave de la iglesia difícilmente podrá salvarse. D esde su interior muestra las rajaduras de la bóveda por entre las cuales pasa la lluvia que cae y se tamiza en partículas luminosas, como aquellas del mito que fecundaron a $D$ anae. Vista desde abajo y al revés, esta bóveda produce el vértigo de un casco de navío a punto de zozobrar, con sus costados escupiendo estopa y sus tablas rompiéndose en astillas por los gol pes del mar.

Al claustro he llegado tres veces con triste periodicidad. No tengo un documento que confirme su hechura por fray Andrés de San M iguel, pero su semejanza con los de San Ángel, Puebla y Salvatierra me permiten suponerla firmemente. $\mathrm{N}$ i habría razón, por los años en que se construyó el convento, para que los frailes hubieran Ilamado a otro arquitecto. Por sus medidas, su 


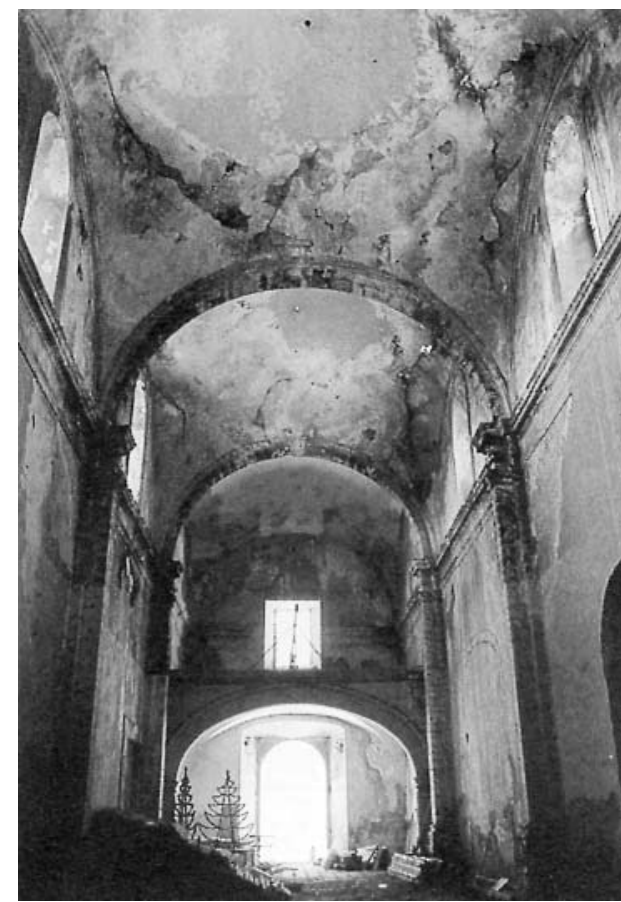

Foto 5. El interior de la nave en 1994. Foto: IIE.

desplante a un solo nivel, su espacio interior y su diseño, se hermana perfectamente con los susodichos, dentro de un arquetipo de enjundiosa arquitectura carmelita.

M i primera visita tuvo lugar hará unos treinta años, cuando el edificio servía de cuartel a un regimiento de caballería. Amablemente, el coronel que estaba al mando nos permitió visitar el convento. La iglesia, utilizada para almacenar el forraje, estaba desnuda pero firme, y en el exterior de la bóveda quedaban algunos vestigios de la espadaña. La entrada al claustro fue una revelación, porque al instante percibimos su parecido con el de San Ángel, aunque ya entonces parecía abandonado y se notaban los primeros daños: yerbas que se extienden rompiendo el piso y matas que agarran sus raíces en las cornisas y la mampostería de las bóvedas. Especialmente simpática era la guía de una calabaza que dejaba caer una flor amarilla partiendo el claro de un arco (foto I).

Para la segunda visita, veinte años después, el convento permanecía ocu- 


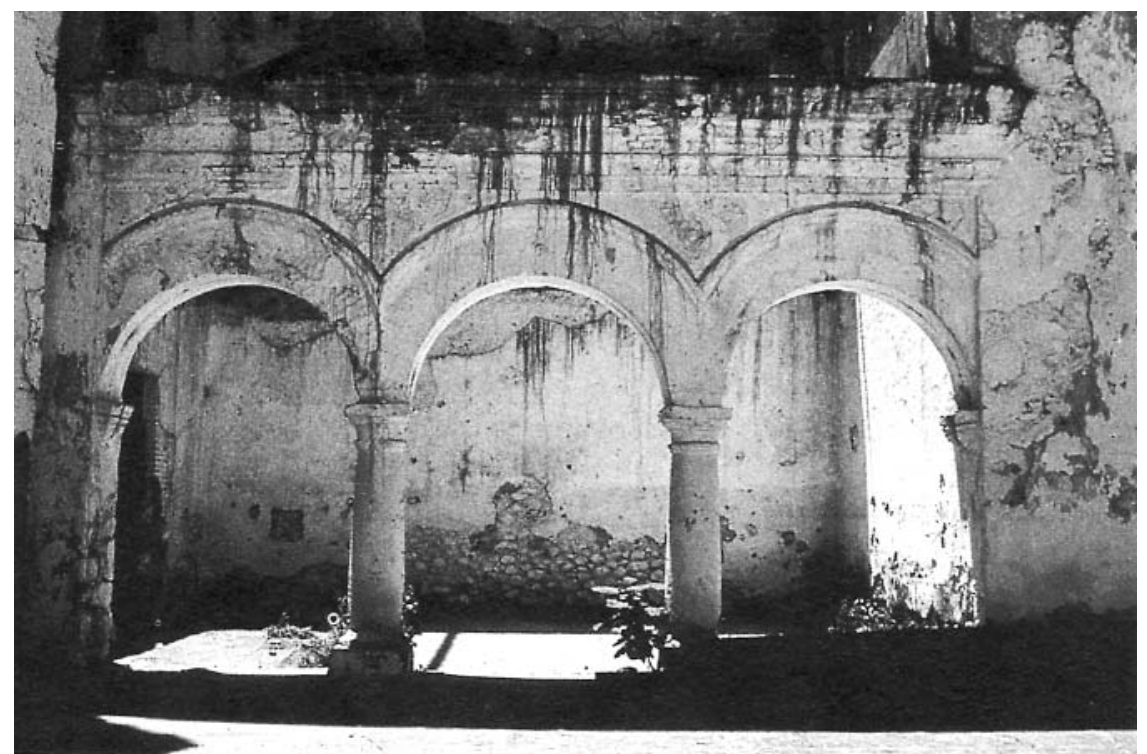

Foto 6. La portería en i994. Foto: E.B.

pado por el ejército. El piso se ocultaba bajo la maleza y las bóvedas se veían en parte fracturadas. Impresionaban las matas, como una gran ola de espuma verde, que se derramaban hasta casi ocultar la arquitectura (fotos 2 y 3 ).

M i tercera visita, hace apenas un año, fue la más triste de todas. Se ha arrancado la vegetación exuberante y el claustro luce ahora desnudo, enseñando las bóvedas rotas y las pilastras que han perdido sus aplanados, quedándose en los huesos, como si un cáncer o lepra les hubiera arrancado los recubrimientos. H ace tiempo que el ejército desocupó el edificio, pero el proceso de muerte continúa. Parece que existe un proyecto de restauración pero no se ve que se trabaje en él. Q ueda, como una visión romántica, la ruina silenciosa, triste y sola, sin más signo de vida que el ruido de los pasos del vigilante haciendo sus rondines (foto 4 ).

Para la historia, para las tradiciones, para la orden del Carmen y la gente de Atlixco éste es un claustro venerable. Sobre sus losas caminaron religiosos ejemplares por sus virtudes (creamos por esta vez a las crónicas) de acuerdo con el relato de fray Agustín de la M adre de Dios. Citemos algunos ejemplos: el hermano M ateo de Jesús M aría, oriundo de la Villa de Almanza, en 
162 EDUARDO BÁEZ M.

Aragón; hábil jugador de manos, diestro en el teatro y en acrobacias, que cambió los tablados por la celda y las mortificaciones. Suelto de pies - decían sus superiores-, pero no de costumbres. D e figura agradable, juvenil y alegre, y dueño de una "soltura de miembros que era admirable el verle". Ya religioso, se disciplinaba y acostaba sobre lecho de nopales, y una de sus mayores al egrías fue que le internaran en la casa de los locos, pues en tan poca cosa se tenía a sí mismo.

Fray Anastasio de la Madre de Dios, emparentado con San Juan de la Cruz e hijo de un padre que, por tener costumbre de lavar los pies a los mendigos que llegaban por su casa, había merecido que D ios mismo le diera a curar sus llagas.

O tros casos se cuentan en la crónica, pero quizá ninguno sea tan interesante como el de una ermitaña (caso único en la Colonia) que vivió en las quebradas de los cerros que circundan la villa y sólo interrumpía su retiro para confesarse en el convento con los carmelitas. El cronista omite el nombre, pero la hace émula de la famosísima Catalina de Cardona. D urante más de treinta años luchó con el demonio; usaba el cabello corto, el hábito del Carmen directamente sobre la carne, los ojos siempre bajos y la cabeza descubierta al sol y la intemperie. D e la leyenda de la Egipciaca el cronista toma prestada la historia de los tres panecillos que le fueron regalados por la Virgen y que renovándose milagrosamente bastaron para alimentarle durante toda su vida de anacoreta.

No se trata solamente de ver cómo un claustro se nos desmorona. H ay muchas cosas relacionadas con él que apenas vamos bosquejando. En el siglo xvir tuvo vida y albergó una comunidad que el padre Agustín compara, por su dulzura y laboriosidad, con las abejas del Hexameron de San Ambrosio. En al guna parte el cronista equipara al convento con un jardín místico.

Yo pienso en el claustro, silencio de cal y mirto, para emplear la metáfora de Federico García Lorca. Y pienso en el mensaje místico de las florecillas que, según dice la crónica, crecían en donde ahora sólo existen los escombros y la escarda: "se ve exhalar a los claveles sangre de penitencia, a las azucenas nieve de castidad, a los jazmines ámbar de devoción, amor a las violetas y al romero esperanzas..." 4 (fotos 5 y 6 ). s 